\title{
Effect of Immunomodulating Adjuvant Dzherelo (Immunoxel) in HIV Infected Patients Receiving Standard Antiretroviral Therapy
}

\author{
Lyudmila G. Nikolaeva ${ }^{1}$, Tatiana V. Maystat ${ }^{1}$, Yuri L. Volyanskii ${ }^{2}$, Volodymyr S. Pylypchuk ${ }^{3}$, \\ Valery M. Frolov ${ }^{4}$ and Galyna A. Kutsyna ${ }^{*}, 4$ \\ ${ }^{I}$ Kharkov Regional AIDS Prophylaxis and Prevention Center, Kharkov Medical Academy of Postgraduate Education, \\ 6 Bor'by Street, Kharkov 61044, Ukraine \\ ${ }^{2}$ I.I. Mechnikov Institute of Microbiology and Immunology, Kharkov 61057, Ukraine \\ ${ }^{3}$ Ekomed LLC., Prospect Pravdy 80-A, Kiev 04208, Ukraine \\ ${ }^{4}$ Luhansk State Medical University and Regional AIDS Center, Luhansk 91045, Ukraine
}

\begin{abstract}
Open-label, matched-case, comparative trial was conducted in $40 \mathrm{HIV}$-infected patients to evaluate the adjunct effect of Dzherelo (Immunoxel) on immune and viral parameters. Arm A $(n=20)$ received anti-retroviral therapy (ART) consisting of zidovudine, lamivudine, and efavirenz and arm B $(n=20)$ received ART with Dzherelo. After 2 months total T-lymphocytes increased in ART recipients from 664 to 819 cells $/ \mu \mathrm{l}(\mathrm{P}=0.06)$, whereas in Dzherelo recipients they rose from 595 to $785(\mathrm{P}=0.03)$. The CD4 T-cells expanded by $57.3 \%$ (218 to $343 ; \mathrm{P}=0.002)$ in the ART arm and by $93.5 \%(184$ to $356 ; \mathrm{P}=0.004)$ in the Dzherelo arm. The accrual in absolute and relative number of CD8+ lymphocytes in ART and in the Dzherelo recipients was $43.2 \%(2.7 \%)$ and $50.4 \%(-0.5 \%)$ respectively. The CD4/CD8 ratio in Dzherelo recipients increased from 1.495 to $1.940(\mathrm{P}=0.03)$ but insignificant in the control: 1.418 to $1.613(\mathrm{P}=0.14)$. Activated CD3+ HLA$\mathrm{DR}+\mathrm{T}$-cells increased from 209 to $264(\mathrm{P}=0.02)$ and from 161 to $348(\mathrm{P}=0.0007)$ in ART and Dzherelo recipients respectively. No changes in CD20+ B-lymphocytes were seen in the control, but in Dzherelo patients they declined from 509 to $333(\mathrm{P}=0.00008)$. The proportion of CD3- CD16+CD56+ NK cells was not affected by ART but addition of Dzherelo raised NK cells from $11.2 \%$ to $17.1 \%(\mathrm{P}=0.0001)$. About three-quarters $(14 / 19)$ of patients on ART displayed decrease in viral load (1718 to 1419 copies/ml; $\mathrm{P}=0.008$ ), while $95 \%$ of patients on Dzherelo had a decrease (1793 to $1368 ; \mathrm{P}=0.001$ ). Dzherelo has a favorable effect on the immune status and viral burden when given as an immunomodulating adjunct to ART.
\end{abstract}

Keywords: AIDS, antiviral, HAART, herbal, immunotherapy, phytotherapy.

\section{BACKGROUND}

Antiretroviral drug resistance, drug toxicity and adherence are major concerns in clinical management of HIV infection [1]. The combination of antiviral drugs, such as highly active antiretroviral therapy (HAART), may prevent HIV from mutating and spreading, allowing patients to rebuild their immune system to the same levels as in normal individuals [2]. On the other hand, the immune activation caused by enhanced immune reaction to HIV is now recognized as a cause of depletion of CD4 T-cells and resulting immunodeficiency [3]. These problems are a driving force for research on new therapies that can provide suitable solutions. The most optimal therapeutic solution is an effective and safe immunotherapy that could regulate the immune response in a manner favorable to the host. There are many types of immune modulators that have been used clinically for viral infections, but for HIV the choice of immune interventions is limited [4].

*Address correspondence to this author at the Department of Infectious Diseases and Epidemiology, Luhansk State Medical University, Luhansk 91045, Ukraine; Tel/Fax: +38-057-392-09-08; E-mail: kutsyna@list.ru
Ukraine has the highest prevalence of HIV infection in Eastern Europe [5, 6]. Oral immunomodulator Dzherelo is used in Ukraine for the management of HIV infections, including patients co-infected with TB [7-12]. Clinical studies have indicated that Dzherelo can significantly increase CD3 and CD4 T-lymphocyte populations and helps to achieve better clinical response when combined with standard antiretroviral therapy (ART) consisting of zidovudine (AZT); lamivudine (3TC), and efavirenz (EFV) [7-9]. Dzherelo has been found to decrease the incidence of opportunistic infections and reverse AIDS-associated wasting [7-9]. Dzherelo has also been found to decrease the hepatotoxicity associated with ART [7-9, 12].

Dzherelo was approved in 1997 by the Ministry of Health of Ukraine as an immunomodulating supplement, which so far has been used by over 500,000 individuals for various indications including chronic bacterial and viral infections such as TB and HIV, autoimmune diseases, and malignancy [7]. Dzherelo contains concentrated aqueous-alcohol extract from medicinal plants such as Aloe, Common knotgrass, Yarrow, Purple coneflower, Tutsan, Centaury, Snowball tree berries, Nettle, Dandelion, Sweet-sedge, Oregano, Marigold, Seabuckthorn fruit, Elecampane, Tormentil, Greater plantain, 
Wormwood, Siberian golden root, Cottonweed, Licorice, Fennel, Birch tree fungus, Thyme, Three-lobe Beggarticks, Sage, Dog rose fruit, and Juniper fruit. Our study was aimed at evaluating the effect of Dzherelo on immune cell subsets and viral load among HIV patients treated with standard ART in comparison to a control population which received ART alone.

\section{MATERIALS AND METHODS}

\section{Patients}

The design of this study is matched case comparative study. The patients, aged 20-59 years, have been selected and divided into arms A (ART alone) and B (Dzherelo added), each consisting of 20 patients matched by their average initial CD4 counts, gender ratio and age. The average (median) age in arms A and B was 33.9 (31.5) and 32.8 (31) years. The proportion of males and females was $15 / 5$ and $17 / 3$ in arms A and B respectively. Patients were in advanced clinical stage of HIV infection with average baseline CD4+ T-cell count being below 200 cells/microliter. Another inclusion criterion was the lack of any form of anti-retroviral therapy prior to the trial. The diagnosis of HIV infection was established by standard ELISA test further confirmed by Western blot analysis. The participation in this trial was voluntary and patients were enrolled only after signing the written consent indicating that they were free to withdraw from the study at any time. The conduct of the trial was approved by the Ethics board of the AIDS center in compliance with the Helsinki declaration.

\section{Treatment Regimens}

None of the patients received anti-retroviral therapy prior to the trial. After initial screening, qualifying patients were randomly divided in two arms: arm A was prescribed: zidovudine (AZT) at $300 \mathrm{mg}$ doses twice-daily; lamivudine (3TC) $150 \mathrm{mg}$ tablets twice-daily, and efavirenz (EFV) 600 $\mathrm{mg}$ dose once-daily. The arm $\mathrm{B}$ received, in addition to the same three-drug ART, twice per day dose of Dzherelo which was given as 50 drops diluted in $100 \mathrm{ml}$ of water.

\section{Immunophenotyping of Lymphocyte Subpopulations}

The samples of peripheral blood of patients with HIV were analyzed using commercially available Clonospectr panel of monoclonal antibodies against surface antigens of lymphocytes (MedBioSpectr, Moscow, Russia). Assays were carried out at study entry and after 1 and 2 months on the therapy. The absolute and percent values of the following subpopulations were assessed in a blinded fashion by fluorescent microscopy: total $\mathrm{T}$ lymphocytes $(\mathrm{CD} 3+)$; helper $\mathrm{T}$ lymphocytes $(\mathrm{CD} 3+\mathrm{CD} 4+)$; cytotoxic $\mathrm{T}$ lymphocytes $(\mathrm{CD} 3+\mathrm{CD} 8+)$; B lymphocytes (CD20+); natural killer or NK cells (CD3-CD16+CD56+); and activated $\mathrm{T}$ lymphocytes $(\mathrm{CD} 3+\mathrm{HLA}-\mathrm{DR}+)$. In addition the changes in the ratio between CD4 and CD8 cells were evaluated as a part of assessment of the immune status of patients. The samples of the blood from 19 healthy blood donors were analyzed as a reference for normal values.

\section{PCR Analysis}

Stored frozen samples of plasma were processed in bulk by using commercially available PCR kit (AmpliSense
HIV-1, Central Research Institute of Epidemiology, Moscow, Russia) designed for quantitative analysis of HIV-RNA copies. Tests were carried out at baseline and after two months of the therapy.

\section{Statistical Analysis}

The obtained results were analyzed with the aid of statistical software STATMOST (Datamost, South Sandy, UT). The baseline cell numbers relative to 1st and 2 nd months of follow-up were evaluated by paired Student t-test. The nonparametric values such as viral load were analyzed by Wilcoxon signed-rank test. All statistical calculations were per intent-to-treat basis or the total number of available patients without subgrouping them into responders and nonresponders. The resulting probability values were considered as significant at the cut-off levels of $\mathrm{P} \leq 0.05$.

\section{RESULTS}

After one month on the therapy there was a clear distinction between recipients of ART alone and those who received ART along with the daily dose of Dzherelo. This disparity became even more evident at the end of $2^{\text {nd }}$ month of therapy. Some but not all immune markers of lymphocyte subsets were impacted in a statistically significant manner. The changes in viral load among HIV patients of both groups also reached statistical significance. These findings are described in detail below.

\section{CD3+ Total T Lymphocytes}

After one month on ART alone the absolute and percent (\%) values of total $\mathrm{CD} 3+$ lymphocytes per microliter of blood changed in a statistically discordant manner i.e. from a baseline $664(36.5 \%)$ to $743(38.4 \%)$ with $\mathrm{P}=0.13(\mathrm{P}=0.03)$, as analyzed by paired Student t-test. Similarly, after one month in the group receiving Dzherelo there was a statistical discordance between absolute and percent $\mathrm{CD} 3+$ values: from $595(34.2 \%)$ to $664(40.5 \%) ; \mathrm{P}=0.14(\mathrm{P}=0.0003)$. After 2 months the number of total CD3+ lymphocytes increased further to $785(43.9 \%)$ in arm B (Dzherelo) i.e. $\mathrm{P}=0.034$ $(\mathrm{P}=0.0002)$, whereas in the control it increased to 819 $(39.8 \%)$ cells, with probability values $\mathrm{P}=0.06(\mathrm{P}=0.03)$ respectively. The accrual in total lymphocytes from baseline to the end of follow-up, was $23.3 \%$ and $31.9 \%$ for absolute and $9 \%$ and $28.4 \%$ for relative numbers in control and Dzherelo arms respectively (Fig. 1).

\section{CD4+ T Lymphocytes}

The trends similar to those of total CD3+ lymphocytes were observed when $\mathrm{CD} 3+\mathrm{CD} 4+$ lymphocyte subsets were analyzed. Significant changes were seen in the ART alone arm after one month i.e. $218(30.3 \%)$ to $295(35.2 \%)$; $\mathrm{P}=0.007(\mathrm{P}=0.02)$. Similarly in the Dzherelo arm the helper T-cell counts rose in a significant manner from $184(28.4 \%)$ to $254(34.8 \%)$ cells; $\mathrm{P}=0.03(\mathrm{P}=0.0002)$. At the end of $2^{\text {nd }}$ month lymphocyte subsets rose to $343(35.7 \%)$ and $356(38 \%)$ with probability values $\mathrm{P}=0.002(\mathrm{P}=0.01)$ and $\mathrm{P}=0.004$ $(\mathrm{P}=0.0005)$ for arms $\mathrm{A}$ and $\mathrm{B}$ respectively. When study completion results of ART and Dzherelo recipients were calculated in terms of accrual in CD4+ lymphocytes relative to entry levels there was an increase of $57.3 \%(17.8 \%)$ and $93.5 \%(33.8 \%)$ in absolute and relative values. 


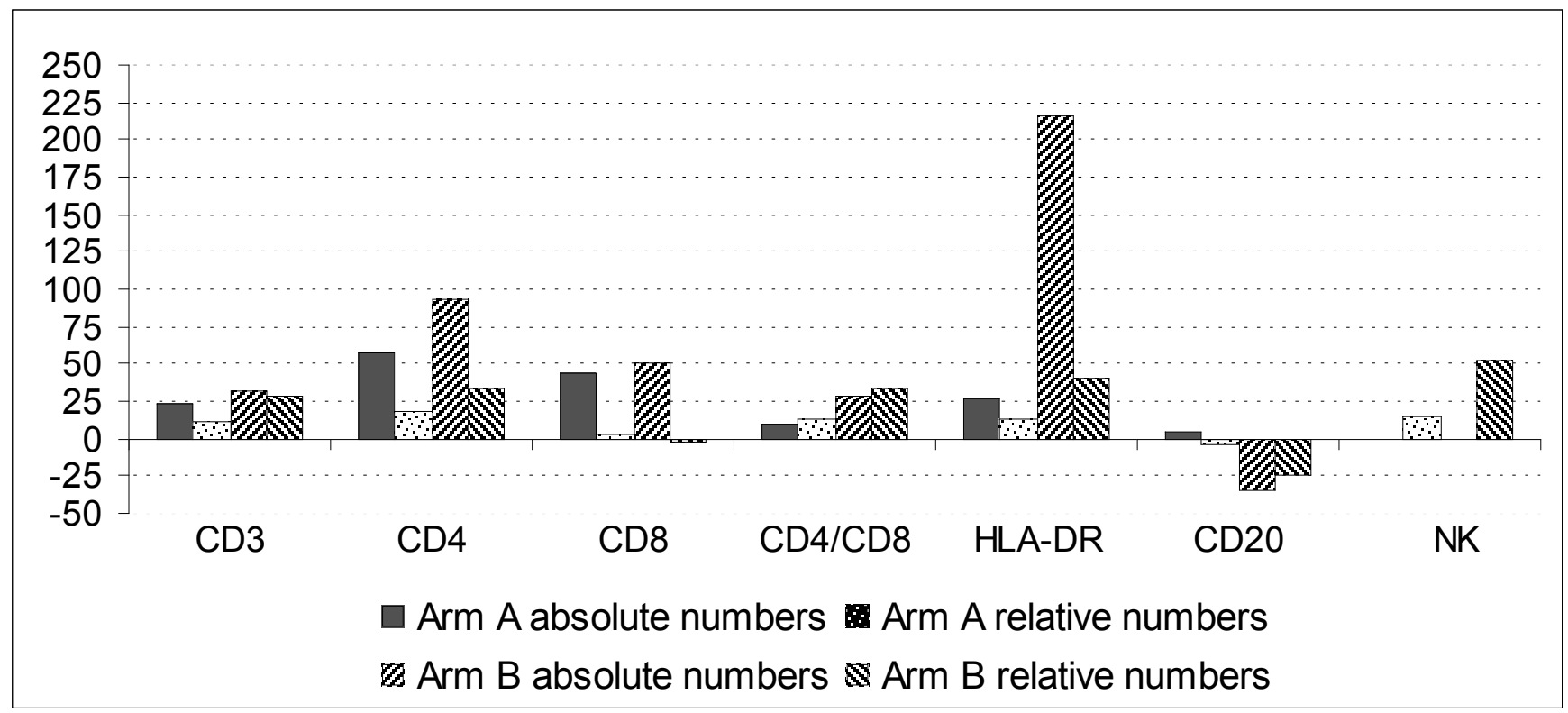

Fig. (1). Changes in absolute and relative numbers of peripheral blood cell subpopulations at 2 months post-therapy as expressed in percentage values ( $\mathrm{Y}$-axis) relative to their respective baseline levels.

\section{CD8+ T Lymphocytes}

The changes observed in CD3+CD8+ cytotoxic T-cell population are different from those seen with helper cells. In the ART alone group, absolute but not relative numbers of CD8+ cells increased in a significant manner from $155(22.6 \%)$ to $203(24 \%) ; \mathrm{P}=0.014(\mathrm{P}=0.21)$, while in the Dzherelo group the changes were insignificant in both categories i.e. from $123(19.8 \%)$ to $152(20.3 \%) ; \mathrm{P}=0.08(\mathrm{P}=0.28)$. At the end of the $2^{\text {nd }}$ month the CTL population in the ART group was still above baseline i.e. 222 cells (23.2\%), an accrual that was statistically significant for absolute numbers $\mathrm{P}=0.009$ but not significant when relative numbers were evaluated $(\mathrm{P}=0.39)$. Similarly, among Dzherelo recipients the $2^{\text {nd }}$ month absolute but not relative numbers of CD8 cells also increased in a significant manner, from baseline levels $123(19.8 \%)$ to $185(19.7 \%)$, with $\mathrm{P}$ values being 0.013 and 0.39 respectively. When study completion results of ART and Dzherelo recipients were calculated in terms of accrual in CD8+ lymphocytes as compared to baseline levels there was an accrual corresponding to $43.2 \%(2.7 \%)$ and $50.4 \%(-$ $0.5 \%$ ) of absolute and relative values respectively.

\section{CD4/CD8 Ratio}

The differential changes in CD4 and CD8 lymphocyte numbers affected the CD4/CD8 ratio in patients on ART alone regimen as early as one month after treatment initiation. The ratio increased from baseline value 1.418 to 1.532 but without reaching significance $(\mathrm{P}=0.23)$. The $\mathrm{CD} 4 / \mathrm{CD} 8$ ratio among Dzherelo recipients increased from 1.495 to 1.671 , which was also above the cut-off value $(\mathrm{P}=0.09)$. The disparity between CD4 and CD8 lymphocytes had progressed further by the end of $2^{\text {nd }}$ month. Among the ART alone patients the ratio increased to $1.613(\mathrm{P}=0.14)$, while in Dzherelo group the ratio rose to $1.940(\mathrm{P}=0.03)$. When study end results of ART and Dzherelo recipients were calculated in terms of relative accrual from baseline levels there was a gain of $13.8 \%$ and $29.3 \%$ respectively.

\section{CD3+HLA-DR+ Activated Lymphocytes}

The absolute and percent numbers of activated CD3+HLA-DR + $\mathrm{T}$ cells increased steadily in ART group from $209(24.7 \%)$ to 231 (26.6\%), and then to $264(27.8 \%)$ with $\mathrm{P}=0.13(\mathrm{P}=0.04)$ and $\mathrm{P}=0.02(\mathrm{P}=0.02)$ at the end of first and second months respectively. In Dzherelo recipients this subpopulation increased at higher incremental rate from $161(25.9 \%)$ to $247(35.1 \%)$ and then to $348(36.5 \%)$ with $\mathrm{P}=0.01(\mathrm{P}=0.0004)$ and $\mathrm{P}=0.0007(\mathrm{P}=0.0003)$ respectively. The relative accrual in absolute and relative numbers in ART group was $26.3 \%(12.6 \%)$ at the end of the $2^{\text {nd }}$ month. During the same time period the patients who received Dzherelo experienced $216 \%(40.9 \%)$ increase over baseline in absolute and relative numbers respectively.

\section{CD20+ B Lymphocytes}

In patients who received ART alone B-cell counts moved up slightly but differences were not statistically significant at either time point. At the end of the $1^{\text {st }}$ month they rose from $522(28.3 \%)$ to $526(28.2 \%)$ cells $\mathrm{P}=0.43(\mathrm{P}=0.37)$ and at study conclusion they reached $542(27.3 \%) ; \quad \mathrm{P}=0.47$ $(\mathrm{P}=0.22)$. However, patients who received Dzherelo displayed a significant decrease in $\mathrm{CD} 20+$ lymphocyte numbers. The entry value of $509(31 \%)$ cells went down to 367 $(24.9 \%)$ at the $1^{\text {st }}$ month and then to $333(23.3 \%)$ toward end of the study with probability values $\mathrm{P}=0.003(\mathrm{P}=0.0002)$ and $\mathrm{P}=0.00008(\mathrm{P}=0.00002)$ respectively. At this time point the number of CD20-expressing cells became indistinguishable from the value of normal donors i.e. 337 cells $(22.2 \%)$.

\section{CD3-CD16+CD56+ NK Cells}

The relative numbers of NK cells identified as CD3negative but CD16+CD56+ population were not significantly affected by ART alone therapy: from baseline level of $19.3 \%$ they rose to $21.2 \%(\mathrm{P}=0.17)$, and then to $22.3 \%$ at study conclusion $(\mathrm{P}=0.12)$. The addition of daily dose of Dzherelo, however, had a strong effect on gain of NK cells. The 
patients who started with an average $11.2 \%$ NK cells had their numbers increased to $13.7 \%(\mathrm{P}=0.004)$, which further increased to $17.1 \%(\mathrm{P}=0.0001)$. Thus, at the end of 2 -month of therapy, the patients on Dzherelo had experienced $52.7 \%$ increase in NK cells as compared to baseline levels.

\section{Lymphocyte Subsets in Normal Blood Donors}

Samples of the peripheral blood of 19 healthy individuals were analyzed to obtain the normal distribution values of peripheral blood subsets. The average number of absolute and relative (\%) CD3 lymphocytes were $1,370 \pm 169$ cells $/ \mu 1$ (52.9 \pm 6.8$)$. The values of CD4 and CD8 lymphocytes were $622 \pm 89(35.9 \pm 4.3)$ and $349 \pm 42(19.9 \pm 2.1)$ respectively, with the ratio being $1.76 \pm 0.19$. The HLA-DR+ expressing activated T-cells represented $585 \pm 131$ cells $(35.2 \pm 3.5)$. The absolute and percent figures of CD20+ B-lymphocytes per $\mu 1$ of blood were $337 \pm 52(22.2 \pm 4.3)$. The percentage of $\mathrm{NK}$ cells was $12.2 \pm 2.9 \%$.

\section{Viral Load}

The viral load, as measured by plasma RNA-PCR at baseline and at the end of $2^{\text {nd }}$ month, decreased in the ART group (1718 to 1419 copies $/ \mathrm{ml} ; \mathrm{P}=0.008$ ), as analyzed by
Wilcoxon signed rank test. In the Dzherelo arm the viral load decreased from 1793 to 1368 copies; $\mathrm{P}=0.001)$. About threequarters (14/19) of patients on ART alone displayed the decrease in viral load, while 18 out of 19 of patients on Dzherelo $(95 \%)$ had a reduction in their number of viral copies (Table 1).

\section{DISCUSSION}

In prior studies Dzherelo has been shown to influence positively CD3 and CD4 lymphocyte numbers [7-9]. Dzherelo reduced the incidence of opportunistic infections and reversed body weight loss associated with HIV [7, 10]. It has also been shown to reduce the toxic side effects of ART, hepatotoxicity in particular [7, 9, 12]. For example, elevated liver aminopeptidase ALT and AST levels caused by ART have been shown to return back to normal levels when Dzherelo is used. However, these studies have not dealt with the effect of Dzherelo on other immune markers and viral load.

Our 2-month study conducted in prior anti-retroviral drug-naïve population reveals that when Dzherelo is added to ART there are significant benefits associated with this

Table 1. Effect of 2-Month ART without or with Dzherelo on HIV-RNA Plasma Levels

\begin{tabular}{|c|c|c|c|c|c|c|}
\hline \multirow{2}{*}{$\begin{array}{l}\text { Patient } \\
\text { No. }\end{array}$} & \multicolumn{3}{|c|}{$\begin{array}{l}\text { Arm A } \\
\text { HIV Patients on ART Alone }(\mathrm{N}=\mathbf{2 0})\end{array}$} & \multicolumn{3}{|c|}{$\begin{array}{c}\text { Arm B } \\
\text { HIV Patients on ART + Dzherelo }(\mathrm{N}=\mathbf{2 0})\end{array}$} \\
\hline & $\begin{array}{l}\text { HIV-RNA Copies/ml } \\
\text { at Baseline }\end{array}$ & $\begin{array}{l}\text { HIV-RNA Copies/ml } \\
\text { at } 2^{\text {nd }} \text { Month }\end{array}$ & $\begin{array}{l}\text { Difference Com- } \\
\text { pared to Baseline }\end{array}$ & $\begin{array}{l}\text { HIV-RNA Copies/ml } \\
\text { at Baseline }\end{array}$ & $\begin{array}{c}\text { HIV-RNA } \\
\text { Copies/ml at } 2^{\text {nd }} \\
\text { Month }\end{array}$ & $\begin{array}{c}\text { Difference } \\
\text { Compared to } \\
\text { Baseline }\end{array}$ \\
\hline 1 & 847.2 & 473.5 & -373.7 & 952.2 & 421.2 & -531 \\
\hline 2 & 1756.8 & 1308.3 & -448.5 & 1353.0 & 789.1 & -563.9 \\
\hline 3 & 978.1 & 1123.6 & +145.5 & ND & ND & ND \\
\hline 4 & 2564.3 & 1141.2 & -1423.1 & 3899.1 & 1854.4 & -2044.7 \\
\hline 5 & 345.4 & 96.1 & -249.3 & 818.4 & 379.1 & -439.3 \\
\hline 6 & 2053.0 & 1845.1 & -207.9 & 1938.0 & 956.3 & -981.7 \\
\hline 7 & 763.2 & 1295.1 & +531.9 & 2501.4 & 2296.1 & -205.3 \\
\hline 8 & 1537.0 & 867.1 & -669.9 & 783.5 & 1394.6 & +611.1 \\
\hline 9 & 894.2 & 778.0 & -116.2 & 464.3 & 235.1 & -229.2 \\
\hline 10 & 7442.1 & 7601.4 & +159.3 & 937.3 & 562.1 & -375.2 \\
\hline 11 & 346.4 & 189.3 & -157.1 & 1558.1 & 1415.4 & -142.7 \\
\hline 12 & 3178.2 & 2723.1 & -455.1 & 10136.5 & 10112.1 & -24.4 \\
\hline 13 & 237.0 & 91.3 & -145.7 & 539.0 & 241.3 & -297.7 \\
\hline 14 & 881.3 & 922.4 & +41.1 & 669.4 & 314.2 & -355.2 \\
\hline 15 & 1045.0 & 851.1 & -193.9 & 1749.4 & 958.2 & -791.2 \\
\hline 16 & 2339.3 & 1911.0 & -428.3 & 973.6 & 689.1 & -284.5 \\
\hline 17 & 473.1 & 529.4 & +56.3 & 889.7 & 564.2 & -325.5 \\
\hline 18 & 3088.2 & 2064.3 & -1023.9 & 2377.1 & 1918.4 & -458.7 \\
\hline 19 & ND & ND & $\mathrm{ND}$ & 254.5 & 99.4 & -155.1 \\
\hline 20 & 1865.5 & 1141.1 & -724.4 & 1271.3 & 788.3 & -483 \\
\hline Statistics & $\begin{array}{c}\text { Mean } \pm \mathrm{SD}= \\
1717 \pm 1660 \\
\text { Geometric mean }=1199 \\
\text { Median }=1045\end{array}$ & $\begin{array}{c}\text { Mean } \pm \mathrm{SD}= \\
1419 \pm 1650 \\
\text { Geometric } \text { mean }=876 \\
\text { Median }=1124\end{array}$ & $\begin{array}{c}\text { Mean } \pm \mathrm{SD}= \\
-299 \pm 448 \\
\text { Geometric } \\
\text { mean }=272 \\
\text { Median }=208 \\
\text { Wilcoxon signed } \\
\text { rank test; } \mathrm{P}=0.008\end{array}$ & $\begin{array}{c}\text { Mean } \pm \mathrm{SD}= \\
1792 \pm 2202 \\
\text { Geometric } \\
\text { mean }=1222 \\
\text { Median=974 }\end{array}$ & $\begin{array}{c}\text { Mean } \pm \mathrm{SD}= \\
1368 \pm 2208 \\
\text { Geometric } \\
\text { mean=762 } \\
\text { Median=788 }\end{array}$ & $\begin{array}{c}\text { Mean } \pm \mathrm{SD}= \\
-425 \pm 507 \\
\text { Geometric } \\
\text { mean }=353 \\
\text { Median }= \\
-355 \\
\text { Wilcoxon } \\
\text { signed rank } \\
\text { test; } \mathrm{P}=0.001\end{array}$ \\
\hline
\end{tabular}


intervention. In our hands Dzherelo appears to display the same effect as reported by independent investigators. Our results indicate that administration of Dzherelo along with ART can produce significant increase in total $\mathrm{CD} 3+$ lymphocytes, CD4+ helper cells, better CD4/CD8 ratio, higher number of CD3+HLA-DR+ activated lymphocytes, and NK cells. Dzherelo appears to increase absolute but not relative numbers of $\mathrm{CD} 8+\mathrm{T}$ lymphocytes and reduce significantly CD20+ B lymphocyte subpopulation. Furthermore, Dzherelo appears to contribute to the inhibitory effect of ART on viral replication resulting in statistically significant lower viral load in a higher proportion of patients (Table 1). These effects could not be attributed to heterogeneity of patient populations in two tightly matched treatment groups in which none of the initial characteristics in terms of age, gender, disease stage and cell counts were statistically different at baseline.

It is well established that elevated CD3 and CD4 counts and higher $\mathrm{CD} 4 / \mathrm{CD} 8$ ratio are associated with better prognosis in patients with HIV [13]. For this reason Dzherelo is likely to influence positively the outcome of treatment and disease progression in our study population. Similarly, viral load is a predictor of HIV disease progression, its persistent elevation in HIV infected patients being indicative of poor prognosis $[14,15]$. While there were earlier indications that Dzherelo may reduce the viral burden, our study is the first to report this phenomenon in a systematic fashion. Despite the fact that the HIV RNA levels had decreased by less than a $\log$ the difference between baseline and outcome levels was highly significant (Table 1). While baseline and outcome viral burden appeared unusually low, this may have been due to the PCR kit we have used in this study; since we have seen similar low numbers in our study dealing with TB/HIV dually infected patients [10]. Nevertheless, it is likely that the observed effect on viral load is mediated by immune cells since Dzherelo does not have a direct effect on HIV replication [7].

Our study reveals that at the end of study the patients on Dzherelo had absolute and relative numbers of CD3+HLADR+ cells equal to $348(36.5 \%)$ or $216 \%$ and $40.9 \%$ more compared to baseline, whereas patients on ART had their numbers increased to a maximum $26.3 \%$. Compared to normal blood donors the relative numbers in Dzherelo group were comparable but absolute values were lower i.e. $35.2 \%$ and 585 respectively. It has been shown that HIV+ patients usually have significantly higher HLA-DR expressing cells, which may negatively affect $\mathrm{T}$ cell immune responses and facilitate the disease progression [16]. Others suggested that the increase in HLA-DR-reactive T lymphocytes was not predictive of clinical outcome [17]. We do not know to which subpopulation of T lymphocytes the CD3+HLA-DR+ activated cells belong. Judging from relative changes in CD4 and CD8 subsets it is possible that the activation marker is expressed on CD4 cells. However, due to limitations of the commercially available panel of antibodies preventing simultaneous staining with multiple fluorescent markers, we have not been able to verify this possibility. This needs to be ascertained in future studies.

Although a great deal of information is available about the role of $\mathrm{T}$ lymphocytes in the immune response against HIV comparatively little is understood regarding the in- volvement of B lymphocytes. Our results show very little variation in $\mathrm{CD} 20+\mathrm{B}$-cell numbers in the ART-treated arm but a highly significant decrease in Dzherelo recipients to levels that were identical to those seen in normal individuals i.e. $333(23.3 \%)$ vs 337 (22.2\%). Contrarily, the absolute and relative numbers of B-cells were more than double in ART recipients. We do not know what the significance of this observation is. It has been reported that the expression of CD20 is consistently higher when B cells from HIV-infected individuals are compared with those from uninfected subjects [18]. Thus, we can only assert that Dzherelo is highly effective in restoring the normal balance of CD20 expressing B-cells.

We have observed the drastic difference between two arms in relative number of NK cells after 2 months of therapy. When compared to the entry levels the patients on Dzherelo had $52.7 \%$ more of NK cells whereas the population of these cells had increased by only $15.5 \%$ in ART alone group. The role of NK cells in HIV remains unclear. While some indicated that higher number of NK cells is critical for controlling HIV, others indicated that the quality but not the number of cells is critical in defending the host against HIV infection $[19,20]$. This discrepancy probably stems from differences in the design of studies some of which were based on measurement of functional activity but others were based on the enumeration of cells at various stages of the disease. Since we have not measured the functional activity of NK cells we do not know what is the significance of this phenomenon in regard to the immunopathogenesis of HIV. Based on the evidence that Dzherelo is highly effective as an immune adjuvant to ART we can only speculate that in our case the increase in NK numbers might be beneficial to the host.

Many studies have been conducted aimed at determining the phenotype of immune cells in HIV infection. While there is a consensus that the immune response plays a critical role in determining the clinical outcome much more has to be learned in order to have a clear picture of cellular events during the course of disease. The understanding of the immune mechanism controlling HIV may result in design of better vaccines and immunotherapies. Therefore, high priority should be given to efforts of prevention and treatment of infectious complications in these patients.

Currently available chemotherapy for the treatment of HIV is not ideal, requiring multiple drugs to be taken in combination for the rest of life of a patient [1]. The extended duration of therapy, coupled with the side effects, often results in poor patient adherence, treatment failure, and the emergence of drug resistance with major social and economic implications. We believe that immunotherapy is an indispensable part of therapeutic strategies against HIV. The development of novel immune-based therapies is an urgent objective for anti-HIV drug discovery. Many immune interventions are available against bacteria, protozoa, fungi and viruses. While often effective the mechanism of many immunomodulators is poorly understood. This downside should be balanced against clinically confirmed benefits. Our study provides an early glimpse into the putative immune mechanism of Dzherelo, which has been successfully used as an immune adjunct to HIV therapy in Ukraine during last ten years [7-12]. Additional studies are needed to develop better 
understanding of Dzherelo's properties and to supplement the current arsenal of HIV therapies.

\section{ACKNOWLEDGEMENTS}

We thank all participants who volunteered in this study. The generosity of Ekomed in supplying Dzherelo is appreciated very much. The tireless support of clinical staff and technicians who contributed to this study has been of tremendous help to bring this study to fruition. The discussion with other investigators of Dzherelo who shared their insight and provided helpful suggestions has guided our study and we are thankful to them all. This work was presented in part at the Keystone Symposia on HIV Pathogenesis and HIV Vaccines, March 27 - Apr 1, 2008, Banff, Alberta, Canada, through a grant from Bill and Melinda Gates Foundation's Global Health Travel Award, which is gratefully acknowledged.

\section{CONFLICT OF INTEREST}

All authors, except Volodymyr Pylypchuk, declare no conflict of interest. Pylypchuk is the inventor of Dzherelo (Immunoxel) and Director of Ekomed company.

\section{ABBREVIATIONS}

$\begin{array}{ll}\text { ART } & =\text { Antiretroviral therapy } \\ \text { EFV } & =\text { Efavirenz } \\ \text { HAART } & =\text { Highly active antiretroviral therapy } \\ \text { HLA } & =\text { Human leukocyte antigen } \\ 3 T C & =\text { Lamivudine } \\ \text { NK } & =\text { Natural killer } \\ \text { PCR } & =\text { Polymerase chain reaction } \\ \text { RNA } & =\text { Ribonucleic acid } \\ \text { TB } & =\text { Tuberculosis } \\ \text { AZT } & \text { Zidovudine } \\ \text { REFERENCES }\end{array}$

[1] Pokrovskii VV. Treatment of HIV-infections: success or crisis? Ter Arkh 2001; 73: 52-4.

[2] Mocroft A, Phillips AN, Gatell J, et al. EuroSIDA study group. Normalisation of CD4 counts in patients with HIV-1 infection and maximum virological suppression who are taking combination antiretroviral therapy: an observational cohort study. Lancet 2007; 370: 407-13.

[3] Appay V, Boutboul F, Autran B. The HIV infection and immune activation: "to fight and burn". Curr Infect Dis Rep 2005; 7: 473-9.
[4] Ershov FI. Use of immunomodulators in viral infections. Antibiot Khimioter 2003; 48: 27-32.

[5] Kelly JA, Amirkhanian YA. The newest epidemic: a review of HIV/AIDS in Central and Eastern Europe. Int J STD AIDS 2003; 14: 361-71.

[6] van der Werf MJ, Yegorova OB, Chentsova N, et al. TuberculosisHIV co-infection in Kiev City, Ukraine. Emerg Infect Dis 2006; 12: 766-8.

[7] Chkhetiany R, Pylipchuk V, Argzanova O, et al. Comparative effect of an immunomodulator Immunoxel (Dzherelo) when used alone or in combination with antiretroviral therapy in drug-naïve HIV infected individuals. Int J Biotechnol 2007; 9: 267-76.

[8] Kutsyna G, Chechitiany R, Bascacov I, Zagaydanova E, Zaharova I. Influence of a novel immunomodulator on the prevalence of new events of opportunistic infections in untreated HIV-infected individuals. 3rd European HIV Drug Resistance Workshop. Athens, Greece. April 4-7, 2005. Abstract \#36.

[9] Prihoda ND, Arjanova OV, Yurchenko LV, et al. Adjuvant immunotherapy of tuberculosis in drug-resistant TB and TB/HIV coinfected patients. Int J Biomed Pharm Sci 2008; 2: 59-64.

[10] Nikolaeva LG, Maystat TV, Pylypchuk VS, Volyanskii YuL, Masyuk LA, Kutsyna GA. Effect of oral immunomodulator Dzherelo (Immunoxel) in TB/HIV co-infected patients receiving anti-tuberculosis therapy under DOTS. Int Immunopharmacol 2008; 8: 845-51.

[11] Nikolaeva LG, Maystat TV, Pylypchuk VS, Volyanskii YL, Masyuk LA, Kutsyna GA. Changes in CD4+ T-cells and HIV RNA resulting from combination of anti-TB therapy with Dzherelo in TB/HIV dually infected patients. Drug Des Dev Ther 2008; 2: 8793.

[12] Zaitseva SI. Clinical efficacy of phytopreparation Dzherelo and its influence on the functional status of liver in patients with destructive forms of tuberculosis. Probl Ecol Med Gen Clin Immunol 2006; 71-72: 132-40.

[13] Bogner JR, Goebel FD. Lymphocyte subsets as surrogate markers in antiretroviral therapy. Infection 1991; 19: S103-8.

[14] Arduino JM, Fischl MA, Stanley K, Collier AC, Spiegelman D. Do HIV type 1 RNA levels provide additional prognostic value to CD4(+) T lymphocyte counts in patients with advanced HIV type 1 infection? AIDS Res Hum Retroviruses 2001; 17: 1099-105.

[15] Dybul M, Fauci AS, Bartlett JG, Kaplan JE, Pau AK. Panel on clinical practices for treatment of HIV. Guidelines for using antiretroviral agents among HIV-infected adults and adolescents. Ann Intern Med 2002; 137: 381-433.

[16] Mahalingam M, Peakman M, Davies ET, Pozniak A, McManus TJ, Vergani D. T cell activation and disease severity in HIV infection. Clin Exp Immunol 1993; 93: 337-43.

[17] Levacher M, Tallet S, Dazza MC, Dournon E, Rouveix B, Pocidalo JJ. Comparison with CD4+ lymphocyte count in non-progressors and progressors towards AIDS. Clin Exp Immunol 1990; 81: 17782.

[18] Ginaldi L, De Martinis M, D'Ostilio A, Marini L, Quaglino D. Changes in antigen expression on B lymphocytes during HIV infection. Pathobiology 1998; 66: 17-23.

[19] Bruunsgaard H, Pedersen C, Skinhoj P, Pedersen BK. Clinical progression of HIV infection: role of NK cells. Scand J Immunol 1997; 46: 91-5.

[20] Alter G, Malenfant JM, Delabre RM, et al. Increased natural killer cell activity in viremic HIV-1 infection. J Immunol 2004; 173: 5305-11. 